\title{
MERCY Malaysia's experience in recent response and rebuilding of disaster areas
}

\author{
S. S. Zubir ${ }^{1}$, M. H. Amirrol ${ }^{2}$ \& R. Ab. Rahman ${ }^{1}$ \\ ${ }^{I}$ Department of Architecture, Planning and Surveying, \\ Universiti Teknologi MARA, Malaysia \\ ${ }^{2}$ MERCY, Malaysia
}

\begin{abstract}
In the last decade, the world has witnessed a multitude of natural disaster ranging from the great tsunami of 2004 to the recent earthquake in Shenzhen, China. Relief efforts from international agencies have contributed in improving the lives of the disaster victims. As a recent established relief organization, MERCY Malaysia's main objective was to assist in medical services but as these areas required major reconstruction interventions, therefore, services from the allied built environment professions have been included in the rebuilding program. The crux of this paper is to chronologically delineate the projects that MERCY MALAYSIA has completed and to highlight the approaches taken in providing the amenities for the internally displaced personnel. The paper will also address the challenges and opportunities for future intervention in improving response and recovery efforts in enhancing sustainable development and establishing a mechanism towards good governance in disaster areas. It is hoped that the paper could excite the dissemination and exchange of expertise, experience and information among the allied built environment professions.
\end{abstract}

Keywords: disaster areas, Total Disaster Risk Management (TDRM), rebuilding and reconstruction, vulnerable communities, safe building, sustainable development, medical facilities.

\section{Introduction}

In 1999, the Balkan war in Kosova caused much suffering to innocent civilians, especially women and children. Grieved by the inhumane situation, Datuk Dr. Jemilah Mahmood, an obstetrics-gynaecologist offered her medical services 
voluntarily. However, there was difficulty in getting the needed support from already established organizations. Thus, she and a few like-minded individuals established the Malaysian Medical Relief Society, better known as MERCY Malaysia in June 1999. Not until the Indian Ocean Earthquake and Tsunami in 2004, did MERCY Malaysia have to diversify its response and relief activities into the spectrum of rebuilding and reconstruction [1]. After the emergency phase ended, most of MERCY Malaysia's medical personnel volunteers were gradually replaced by volunteers within the scope of the built environment architects, engineers of various field, quantity surveyors, water specialists and builders. This transition of professional volunteers was a direct response to the needs of the disaster victims, who had lost their homes, schools, hospitals, etc. This expansion of areas of expertise was done within a short period of time. With the inception of its Technical Team, MERCY Malaysia is committed to analyzing, researching and proposing effective means of disaster management by approaching each of the reconstruction projects carefully. This commitment includes proposing projects and programs which promotes community participation and enabling them to protect themselves against disaster, through Community Based Disaster Risk Management (CBDRM). Another aspect is by trying to achieve an understanding for the public in becoming a prepared and responsive community. This paper will discuss three case studies of such humanitarian projects. These projects were crucial in their planning, designing and implementation. They were fast responses to the need of each country's Department of Health and were designed and implemented in such a way that they will suit the already structured but collapsed health system there. These projects were initiation of the Total Disaster Risk Management (TDRM) concept, in which MERCY Malaysia, during its stay in Indonesia and Myanmar for relief works, not only provided medical relief, basic facilities, houses and public buildings, but also extended its role into educating the community with a long term and self sustaining learning programs [1].

\section{Challenges in rebuilding post-disaster}

The main problem with rebuilding and reconstruction projects after a disaster lay first in the scale of the destruction of buildings and infrastructures and, to a lesser extent, in the poverty of those who suffered the tragedy [2]. In the three worst hit countries of the 2004 Indian Ocean Tsunami - Indonesia, India and Sri Lanka, the majority of people who suffered lived on the margins, on the edge both of the sea and of society. Houses were often fragile and so the violence of the waves rendered extraordinary numbers of people homeless. Along the coasts of Southern India and Sri Lanka, virtually all homes were destroyed in a belt stretching up to half kilometres inland, for hundreds of miles. In Aceh, no houses at all were left standing over many acres of land, and large amounts of land were permanently lost. Almost 700,000 people were made homeless. In addition to these shelter problems, clean water, sanitation and hygiene issues were at the poorest level, contributing to the spread of diseases. With serious defects of medical facilities, these problems had worsened the living standards of the 
disaster victims. After a disaster of such magnitude, defining and classifying needs, quantifying reconstruction activities, financing modalities and resourcing approaches were not easy tasks. The need for a systematic developmental framework is crucial in each of the relief work and intervention. Post-disaster development cannot simply be viewed from the perspective of a single building project. It is not simply a 'problem' to be 'solved'. Rather, these rebuilding programs are complex social redevelopment institutions that interact in many ways with a range of societal issues and surviving daily life in a broader perspective. Consequently, these rebuilding programs can only be addressed responsibly within a broader developmental framework, which addresses the realities of the context. In all disaster-hit areas in poor countries, the most dominant of these realities are poverty, health and education problems, unemployment and scarce resources. A defining condition of poverty and hardships is that it is necessary to pool resources and to work more collectively [3]. Four central dimensions lie at the core of such a developmental framework:

1. The need to stimulate the emergence of qualitatively decent total living/working/learning environments.

2. Identifying the need to use reconstruction and rebuilding initiatives to generate employment.

3. The need to stimulate social cohesion through a reflexive design and planning program.

4. Participative roles of community as an important process.

\section{Stimulating the emergence of qualitatively decent total environments}

A feature of most rebuilding and reconstruction initiatives is their narrow definition into fast and cost effective programs only. The resulting environments are almost poorly designed and built, unfailingly monotonous, sterile and nonsupportive, even when money from external humanitarian aid is reasonably adequate [4]. The quality of these rebuilding projects is not only determined primarily by the quality of a singular building but also by the quality of the public spatial environments. Agencies which work on these programs need to work collectively with proper coordination on a well planned redevelopment blueprint to stimulate a qualitatively decent total environment for living, working, learning and even playing. There is a need for a paradigm shift within the concern of rebuilding a massively destructed disaster-hit area, which thus far has been dominated by two powerful ideologies: the political ideology of building economics and design ideology of standardization. The main concern of this approach is economics and efficiency [5]. The standardization design strategy had replaced rationalist thought with functionalistic design approach. A humanistic, integrative and pragmatic way of thinking which sought to create redevelopment order for urban or rural, in a manner which allowed considerable flexibility of interpretation has become somewhat lost. These vulnerable 
communities would be moving from the old to the new after being affected at large - physically, emotionally and economically. As relief works and rebuilding programs progress, these communities will also be in a motion of uncertainties. Thus, the task of relief workers and architects is to provide a reflexive design and offer a democratization of planning approach. The rebuilding blueprint strategies developed by various local and international agencies such as the United Nations and country's representatives became a key mechanism for the implementation of the reconstruction and development programs for the affected areas. Our task was to further strengthen this blueprint and worked in line with its principle which emphasises the need to enhance the integration of society and economic opportunities and to contribute to the correction of building practices which promotes the idea of safe building for a community at risk.

\section{Roles of community as an important process}

In the $1973 \mathrm{BBC}$ documentary series, The Ascent of Man, Jacob Bronowski regards cities as humanity's greatest act of community co-operation. The fact that disaster happens and people start to work together co-operatively towards a better rebuilding is an extraordinary feat. The British historian, Arnold J. Toynbee once quoted; "The $20^{\text {th }}$ century will be chiefly remembered by future generations not as an era of political conflicts or technical inventions, but as [an] age in which human society dared to think of the welfare of the whole human race as a practical objective" [6]. Every layer of the society should understand support roles and responsibilities. Decision makers and practitioners from NGOs including women's and children organizations to professionals, academicians, students, local authorities, parliamentarians, and community representatives should attain the understanding in being prepared and being able to manage disaster related plans, problems, and solutions. Networking events and programs could provide an intimate venue for practical interaction and exchange. The aims are to build knowledge, strengthen partnerships, create new ones, and provide platforms for sharing novel ideas and practices. Support roles and responsibilities can be divided into two: (a) direct support; and (b) non-direct support [7]. In Aceh and Nias MERCY Malaysia and the local communities had worked together to produce the best approach in problem solving. Good support roles from communities, hospital staffs and other stakeholders from the working group, helped with the successful completion of two community clinics and three phases out of the four-phased planned hospital development.

\section{Selected projects}

\subsection{Community clinics and health facilities, Nias Island, Indonesia}

In March 2005, a strong earthquake with the magnitude of 8.2 at the Richter scale destroyed most part of Nias Island, North of Sumatra, Indonesia. MERCY Malaysia was at that time doing relief works in Aceh, Indonesia due to the December 262004 Indian Ocean Tsunami. Medical evacuation teams were 
deployed directly from Aceh and further assistance from Malaysia was sent to help victims of the disaster in Nias. After the emergency phase ended, technical personnel, who mostly were volunteer architects, engineers and surveyors had assisted in assessing the damage grades and planning of future rebuilding projects. After two weeks of evaluating damaged facilities and analysing the feasibility of planning, design, construction and operational strategies were carried out in consultation with the local beneficiaries. The genius loci of each site became the foundation of our approach. The first construction took site in a very remote village (Desa Awa'ai). The second building was at Hiliweto Gido. Instead of relying on technological approach for rapid and efficient construction, a fairly modern building but with conventional techniques of construction that the local people and builders were familiar with was decided upon (Figure 1). This was driven by the local community's association to the project and their potential employment in it. Through this approach, problems relating to their understanding the purpose of the modern design, which are quite alien for them, were successfully stripped away.

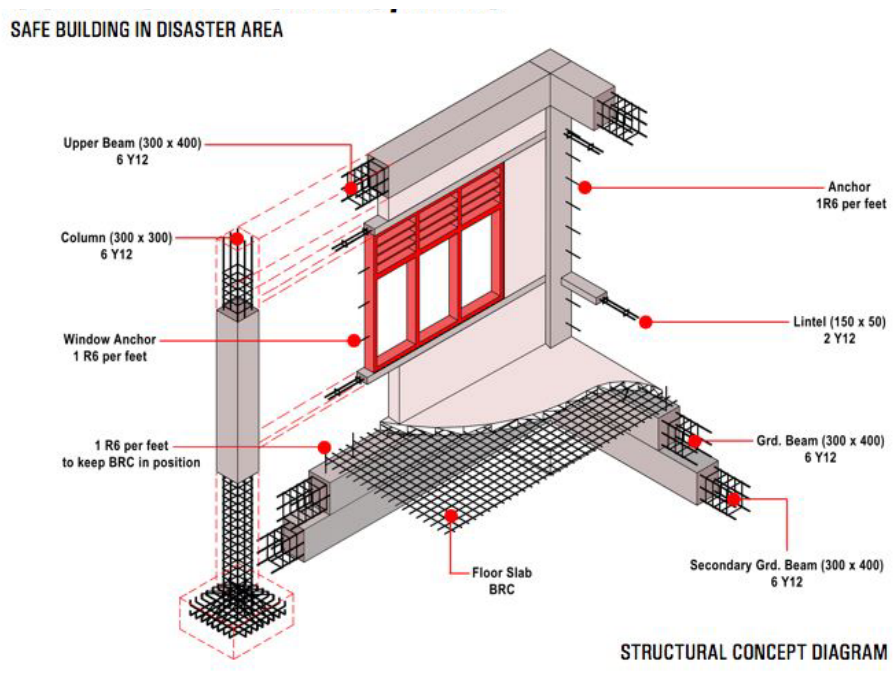

Figure 1: Low technology anti seismic structural concept.

Despite the conventional techniques, the construction methods possessed unique structural characteristics for better seismic resistance behaviour. Collaboration with local engineers and expert from local universities also helped in contextualizing the design scheme and educating the community [8]. This program is important to promote the idea of Total Disaster Risk Management (TDRM), which envisaged the community as having adequate knowledge on risk reduction. The two community clinics were to be a functional building. A liberated multi-purpose space served firstly for evacuation purpose and secondly used to promote public programs to the surrounding community (Figure 2). 


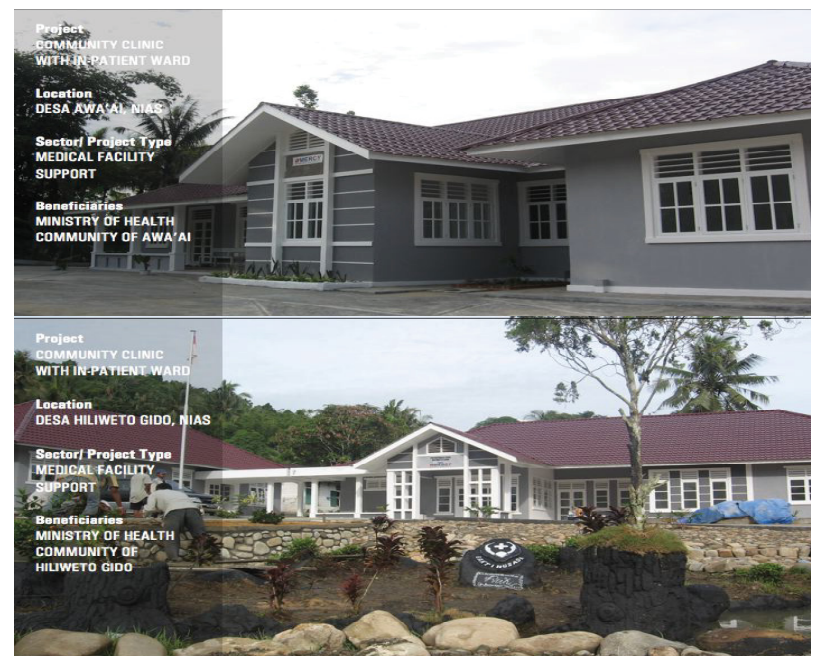

Figure 2: Completed community clinics with multi functioning programs.

\subsection{Gunungsitoli General Hospital, Nias Island, Indonesia}

Health service provision on Nias Island had always been insufficient and became worse after the March 28, 2005 earthquake. The Gunungsitoli General Hospital was one of the major district health facilities heavily damaged. Shortages of doctors and specialists, limited clinical skills of nurses and midwives, poor management and maintenance were worsened. Located in the major town of the isolated island, this hospital serves more than 700,000 populations and is the only referral hospital. The Indonesian Ministry of Health with recommendation from the World Health Organization (WHO) requested for MERCY Malaysia's participation for its reconstruction. This request was made from the good impression shown through earlier humanitarian projects in Aceh. A collective team comprising of architects, medical planners, engineers, surveyors and technicians was deployed to conduct a comprehensive assessment, including a technical report for the Indonesian Government. Damaged grade and design failures of the current hospital were studied thoroughly with the presence of experts in the industry. The master plan included new hospital blocks massing and layout, temporary hospital block, space planning for medical and nonmedical areas, inclusion of a Disaster Management Zone for disaster preparedness and a centralized mechanical and electrical system. In order to ensure the sustainability of investment in revitalizing the hospital, the program was undertaken as a comprehensive intervention. On December 26, 2005, a master plan was presented to the President of Indonesia, Mr. Susilo Bambang Yudhiyono (Figure 3).

The master plan was approved, and detail design proposal was completed within 30 days. The fast design solution was made possible from continuous discussions and workshops, chaired by MERCY Malaysia, alongside with the 


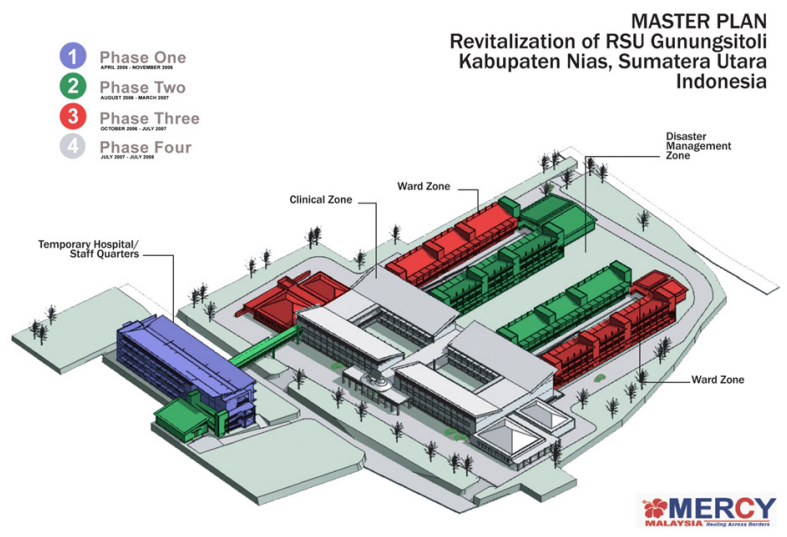

Figure 3: Nias hospital master plan and phasing programs.

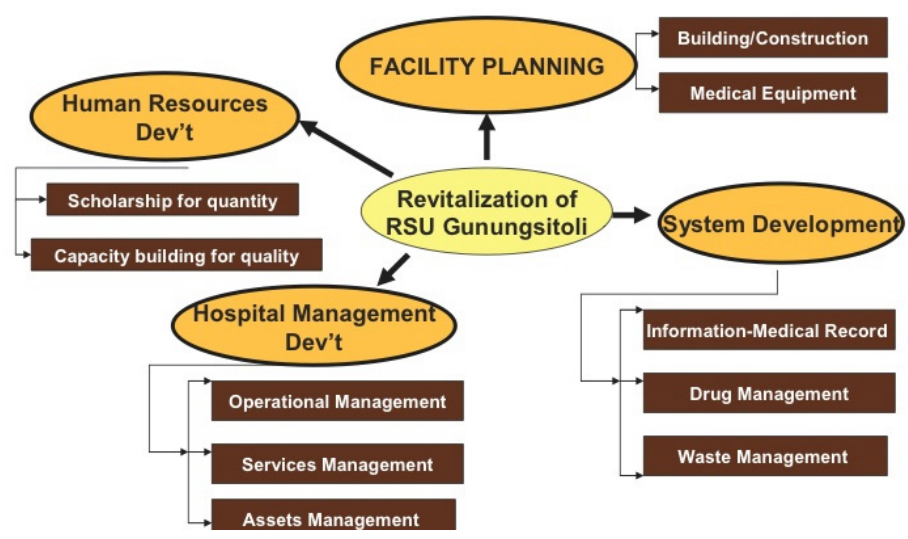

Figure 4: $\quad$ Revitalization concept and sustainability approaches [9].

Hospital's Reconstruction Working Group which comprised the WHO, UNICEF, Indonesian Reconstruction and Rehabilitation Body (BRR) and staffs of the hospital. Public consent was achieved by having continuous presentations and feedback discussion with them. The project scheme comprised facility planning, human resources development, hospital management development, and system development (Figure 4). There were a series of constraints in their implementation, particularly funding. MERCY Malaysia, in collaboration with BRR, played a major role in all four components. The hospital was designed to serve 240 beds. The construction was divided into four phases so as not to interrupt the services while looking for possible donors for each phase (Figure 5). Phase 1 was funded by MERCY Malaysia and constructed as the 

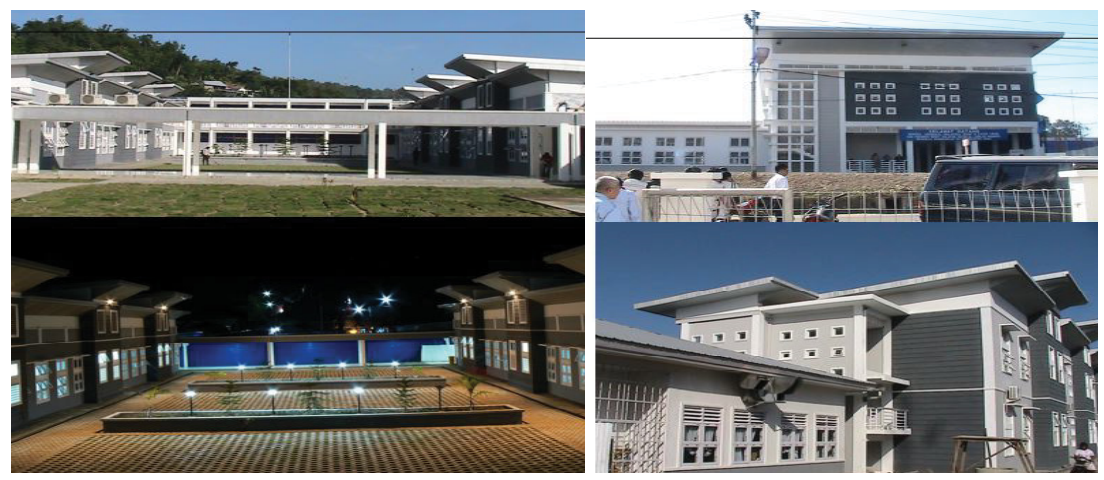

Figure 5: Completed hospital with disaster management zone.

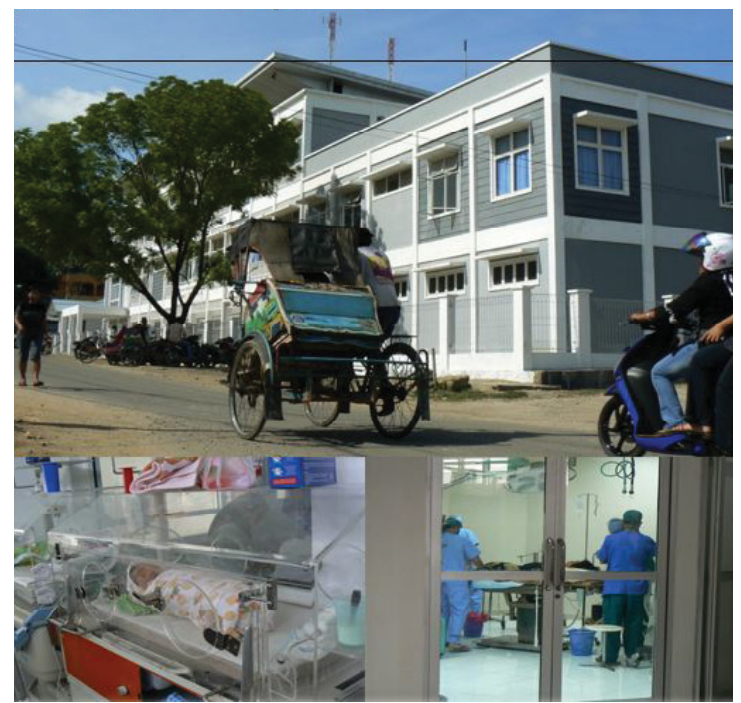

Figure 6: Completed hospital in context.

Maternal and Child Services Wing. This three-storey building was constructed at a cost of USD 1 million. Fund for Phase 2 was provided by the Government of China through the management of BRR and RANTF (Recovery of Aceh and Nias Trust Fund). Phase 2 comprised two wards for Internal Medicine and Surgery Department, kitchen, laundry and the multi function Disaster Management Zone.

Phase 3 was designed to provide services for the Intensive Care Unit, additional Surgery and Internal Medicine wards, Paediatric ward, Outpatients department, pharmacy, mortuary, centralized medical record department and IT department. The Japanese Government through the Japanese International Cooperation System (JICS) funded this USD 5 million building. Phase 4 of the 
construction was located in the centre, facing the main street of the hospital complex. This phase was designated for the Central Operation Theatre, imaging department, laboratory, central sterilization (CSSD), emergency and accident unit, outpatient department, main administrative unit, and medical rehabilitation unit (Figure 6).

\subsection{Rural and Sub-Rural Health Centre, Dedaye District, Myanmar}

On May 2, 2008, Cyclone Nargis made a landfall in Myanmar, causing catastrophic destruction and at least 146,000 fatalities with thousands more missing. It caused the worst natural disaster in the recorded history of Myanmar. Most of the medical facilities in the Dedaye Township were severely damaged. In lieu of bureaucratic difficulties and uncertainties, approval for site inspections was not given. Therefore the mission had been channeled more towards preparing preliminary design concepts for future follow ups. The documents were submitted to the Director General in-charge of international liaison for Myanmar Ministry of Health and the Health Recovery Working Group under the auspices of WHO. The Health Recovery Working Group is an initiative to share information, design ideas, and avoid overlapping of relief works. It is normal during disaster relief efforts, for design and building standards not to be coordinated efficiently, thus resulting in various problems including social jealousy, which will negatively affect the community. MERCY Malaysia and committed organizations for these rebuilding works participated in the Working Group and discussed matters weekly in order to obtain approval from the Government of Myanmar. Work was kept within the locally accepted planning system, and critical discussions were carried out on each NGO's design proposals. MERCY Malaysia was to construct three units of Rural Health Centers and seven units of Sub Rural Health Centers. This commitment meant that MERCY Malaysia was ready to assist the Ministry of Health in rebuilding the damaged health facilities, prepare initial architectural design based on the required needs and local context, gather information on local cost of materials and labors for cost estimation. These exercises were executed within one month, and were soon developed into a workable solution, ready for construction.

Two types of design were proposed, responding to two site conditions: (a) high flood level, and (b) low flood level. The first stressed the idea that the building should become a gathering node for the community. The open spaces around and below the buildings could be utilized for multi-purpose communal functions and acts as a waiting area for patients and their accompanying families. The overall site planning was based on a simple grid layout. The building layout was a simple regular shape that reduced the concentration of pressure built-up and allowed free cross flow of natural ventilation (Figure 7). In cases of high floods levels, an emergency shelter was provided on the second level of the building. PVC tubular tube sun shading devices were fixed around the perimeter of the building. These could be used as rafts for emergency evacuation. The second design option, responding to areas which had lower flood level with stronger soil condition was designed to be constructed on suspended floors, raised three feet above the soil, with basic and simple building form and 


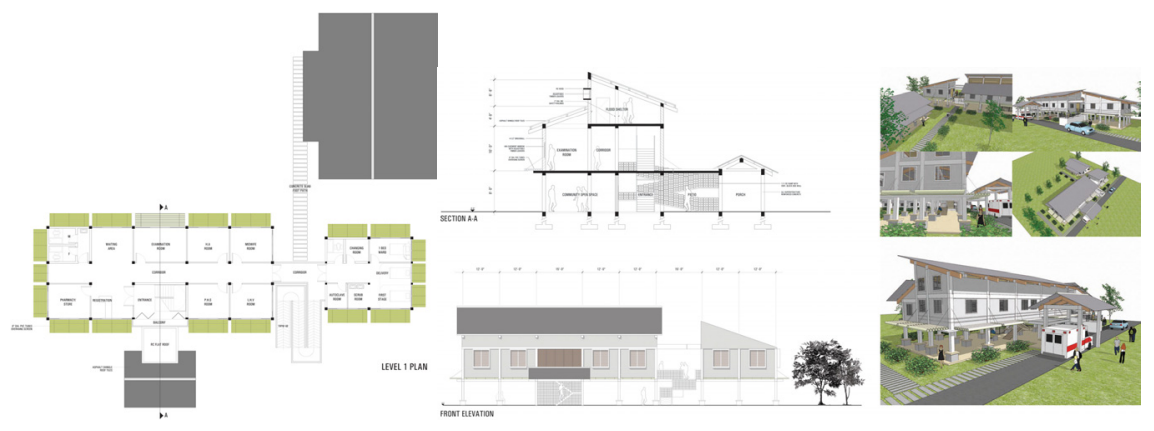

Figure 7: Design proposal for Rural Health Centre.
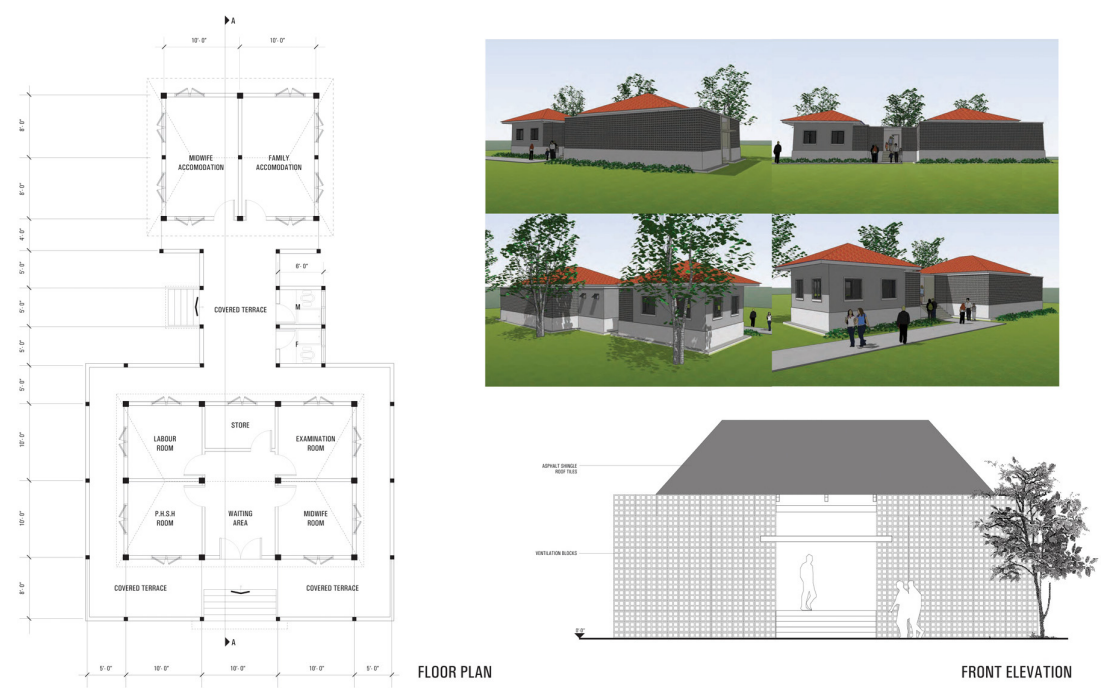

Figure 8: $\quad$ Design proposal for Sub-Rural Health Centre.

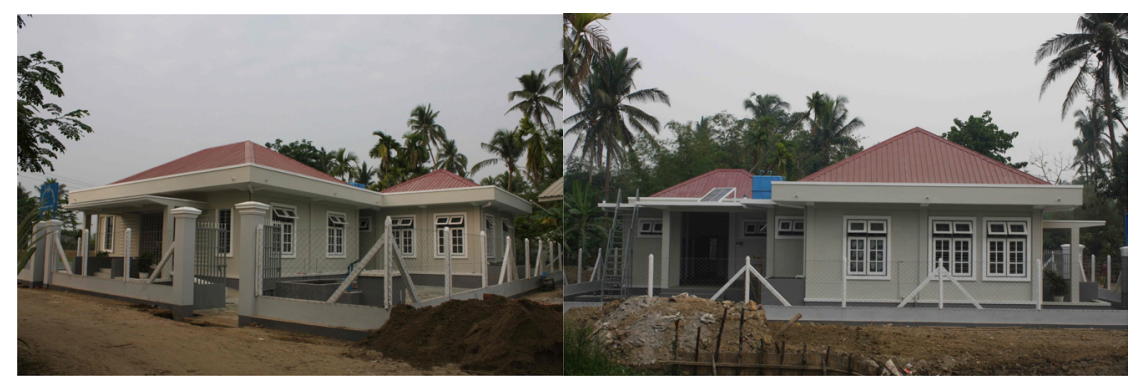

Figure 9: Completed Sub-Rural Health Centre. 
program. The building was intended to represent a safe haven for the community. Ventilation blocks enveloped this health facility, helping to reduce the impact of strong winds and also act as a continuous sunscreen for the covered terraces around it. The overall site planning of the facilities was also based on a simple grid layout. The reinforced concrete flat-roof of the terraces could be used as emergency shelter.

\section{Conclusion}

The interventions in these disaster areas performed a vital function in structuring and organizing knowledge, not only for the beneficiaries, but also for stakeholders and designers in creating a safer and better place to live in, especially in the wild and dangerous areas that are vulnerable to destruction and calamity. Humanitarian works and rebuilding programs have become the interface and access point for the other development activities, ranging from socio-cultural activities to economic revitalization programs to capacity building to the local community at large. It is hopeful that MERCY Malaysia's effort in Indonesia and Myanmar may provide better understanding for agencies and individuals interested in the redeveloping programs post disaster, and will become at least a guiding framework in tackling the myriad of complicated issues. A total disaster risk management methodology must be adapted in order to achieve a sustainable cycle of activities, building performance and economy to help improve the life of the vulnerable communities. This methodology demands a collaborative effort in order to create continuous support for the strategic response and must involve all stakeholders, most importantly, the beneficiaries.

\section{References}

[1] Mahmood, J. (Dr.) (2005) A Time to Heal: A Reflection of MERCY Malaysia's Response to the Indian Ocean Tsunami, The Writers' Publishing House, Kuala Lumpur.

[2] Kuntoro, M. (Dr.) (2005) BRR NAD-Nias: One Year After the Tsunami, BRR First Year Report, Badan Rekonstruksi dan Rehabilitasi Aceh Nias, Jakarta.

[3] Santoso, I. (2005) Lolos Dari Maut Tsunami, Radio 68 H\&Q Communication, Jakarta.

[4] Indonesian Human Development Report 2004 (2004), The Economics of Democracy: Financing Human Development in Indonesia, BPS Statistics Indonesia, BAPPENAS and UNDP, Jakarta.

[5] Hardy, S. (ed.) (2008) Environmental Tectonics: Forming Climatic Change, Architectural Association Agendas No. 6, AA Publications, London.

[6] Toynbee, A. (1957) A Study of History, Oxford University Press, Oxford.

[7] World Food Programme (2002), Emergency Field Pocket Book, United Nations WFP, Rome. 
52 Management of Natural Resources, Sustainable Development and Ecological Hazards II

[8] Collaborative efforts were done with the participation of the Engineering Department, Syiah Kuala University, Aceh, National Society for Earthquake Technology (NSET), Nepal, local builders and volunteering professionals.

[9] BRR NAD-Nias (2007) Concept Note and Proposal for the Revitalization of RSU Gunungsitoli, Nias, Badan Rekonstruksi dan Rehabilitasi Aceh Nias, Jakarta. 